九州大学学術情報リポジトリ

Kyushu University Institutional Repository

Chemosensor of Gold(I) 4-(3,5-Dimethoxybenzy L)3,5-dimethyl Pyrazolate Complex for Quantification of Ethanol in Aqueous Solution

Matheus Randy Prabowo

Ma Chung Research Center for Photosynthetic Pigments, Universitas Ma Chung

Almira Praza Rachmadian

Ma Chung Research Center for Photosynthetic Pigments, Universitas Ma Chung

Nur Fat iha Ghazalli

School of Dental Sciences, Universiti Sains Malaysia

Hendrik 0. Lintang

Department of Chemistry, Faculty of Science and Technology Universitas Ma Chung

https://doi.org/10.5109/4068620

出版情報：Evergreen. 7 (3)，pp.404-408，2020-09. 九州大学グリーンテクノロジー研究教育センター バージョン：

権利関係 : 


\title{
Chemosensor of Gold(I) 4-(3,5-Dimethoxybenzyl)-3,5- dimethyl Pyrazolate Complex for Quantification of Ethanol in Aqueous Solution
}

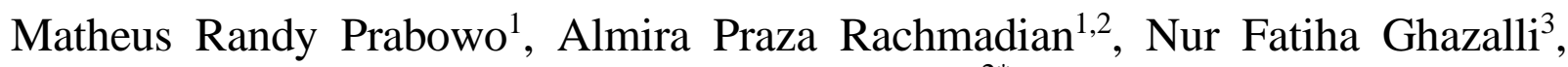 \\ Hendrik O. Lintang ${ }^{2 *}$ \\ ${ }^{1}$ Ma Chung Research Center for Photosynthetic Pigments, Universitas Ma Chung, Villa Puncak Tidar N-01, \\ Malang, 65151, East Java, Indonesia \\ ${ }^{2}$ Department of Chemistry. Faculty of Science and Technology Universitas Ma Chung, Villa Puncak Tidar \\ N-01, Malang, 65151, East Java, Indonesia \\ ${ }^{3}$ School of Dental Sciences, Universiti Sains Malaysia, 16150, Kubang Kerian, Kelantan, Malaysia
}

*Author to whom correspondence should be addressed:

E-mail: hendrik.lintang@machung.ac.id

(Received January 16, 2020; Revised May 31, 2020; accepted September 3, 2020).

\begin{abstract}
By using gold(I) 4-(3,5-dimethoxybenzyl)-3,5-dimethyl pyrazolate complex as a chemosensor, we report a successful quantification of ethanol in aqueous solution based on vaporinduced phosphorescent quenching. Upon monitoring at $278 \mathrm{~nm}$ irradiation, the emission intensity at $609 \mathrm{~nm}$ of the complex was quenched by the presence of ethanol vapors from the mixture. It was found that the intensity is linearly decreased with increment of ethanol concentration where limit of detection was found to be $11.7 \% \mathrm{v} / \mathrm{v}$ in ethanol/water. When the chemosensor was applied to quantify ethanol content of 4 real samples, the accuracy was achieved up to $96 \%$, which is remarkable.
\end{abstract}

Keywords: chemosensor, ethanol, Gold(I) complex, quantification

\section{Introduction}

Ethanol is commonly present in disinfectant, beverage, refrigerant, and it becomes an important reagent in the production of biodiesel ${ }^{1-14)}$. Declaration of ethanol content in the product's label is really required for the regulation and health risk purposes. Therefore, ethanol content monitoring and adsorption due to environmental issues are necessary for the quality control of the products. Ethanol quantification has been done using spectrofluorometer, Fourier transform infrared (FT-IR) spectroscopy, near-infrared (NIR) spectroscopy, and gas chromatography measurements ${ }^{5-7)}$. Those methods have required large-space and high-technology apparatus which could not be directly used in portable applications. Methods in ethanol content determination have been shifted from desktop instrument to be more portable yet accurate. As an example, Marinho et al. reported that ethanol quantification of beverage samples has been evaluated using mobile phone device ${ }^{8)}$. In this case, the acid-base reaction of beverage samples with phenolphthalein in their mixture is required for the evaluation of color intensity changes. This reagent is generally reported as a harmful chemical for human health. However, we have not found other reports for the quantification of ethanol using less harmful of luminescent compounds. Indeed, this chemical sensor (chemosensor) is an indirect interaction of luminescent compounds with vapors of the samples. However, there is no report on the quantification of ethanol using luminescent changes upon interaction with vapor.

Phosphorescence is one of the interesting luminescent properties due to its longer lifetime and bright emission. These phosphorescent properties have been observed in metal azolate complexes such as pyrazolate from its weak metal-metal interaction 15-27). Many applications have been reported using metal pyrazolate complexes due to their characteristics in luminescent changes upon interactions with external stimuli. Considering pyrazolate has an electronegative side, it can form interaction and binding with $-\mathrm{OH}$ of ethanol vapor upon diffusion to the emission site to give phosphorescent changes. Hence, in this work, we report a novel reagent less procedure to quantify the ethanol content using a metal complex with phosphorescent properties named as gold(I) 4-(3,5dimethoxybenzyl)-3,5-dimethyl pyrazolate [1]. The chemical structure of compound [1] was shown in Figure 1. The photoluminescent properties of [1] against ethanol vapor exposure as a vapochromic chemosensor have been 
studied where its emission changes at $609 \mathrm{~nm}$ was used for the detection of ethanol concentration. The limit of detection (LoD) for this approach was found as low as 11.7\%. This proposed method was also applied for the quantification of ethanol in the real disinfectant and beverage products with accuracy up to $96 \%$.

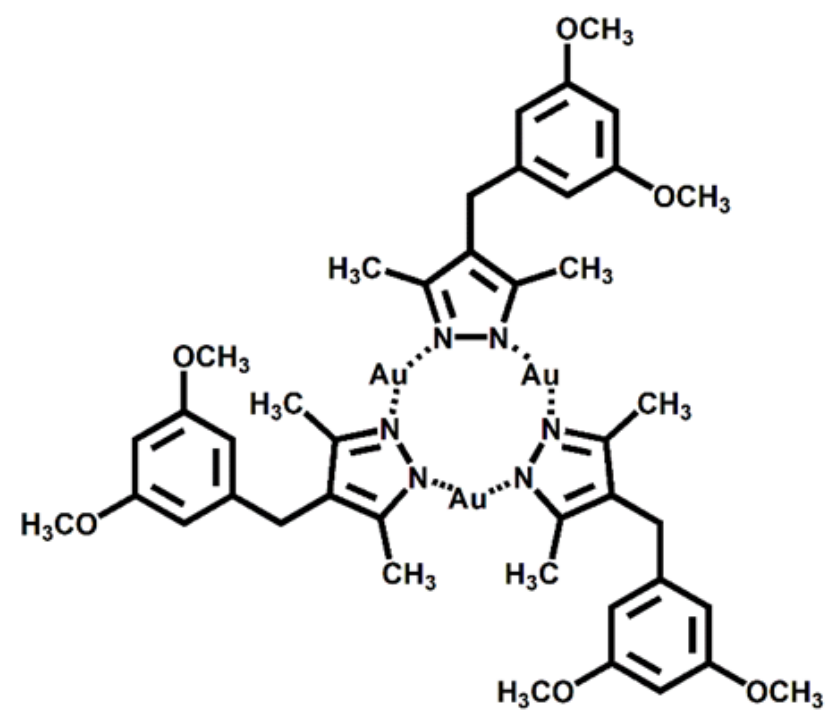

Fig. 1: Molecular structure of gold(I) 4-(3,5dimethoxybenzyl)-3,5-dimethyl pyrazolate complex [1]

\section{Materials and Method}

\subsection{Materials and Instrumentation}

Material [1] as a chemosensor was used as a chemical sensor material. According to the previous method for the synthesis of this complex material [1] ${ }^{15-23)}$, we have firstly prepared pyrazole ligand from 3,5-dimethoxy benzyl bromide in three stepwise reactions under an inert condition. The successful synthesis of the ligand based on characterization using FT-IR spectroscopy and mass spectrometry as reported on our previous report ${ }^{21)}$ was used for the synthesis of complex [1]. By using the same characterization for the synthesis of pyrazole ligand, the isolation of complex [1] in the powder form was clearly confirmed as shown in our report ${ }^{22,23)}$. Ethanol was purchased from Merck in EMSURE® quality. Spectrofluorometric study was done by using JASCO FP8500 spectrofluorometer. For real samples, Onemed Alkohol 95\%, Onemed Alkohol 70\%, Johny Walker ${ }^{\circledR}$ Black Label $\AA$, and Beefeater Gin were used to evaluate the sensing capability.

\subsection{Analytical Procedures}

Various concentrations of ethanol-distilled water mixtures were used as the standard solution with composition of $0 \%, 25 \%, 50 \%, 75 \%$, and $100 \% \mathrm{v} / \mathrm{v}$. As much as $5 \mathrm{mg}$ of sensor material [1] was put into a spectrofluorometer sample holder, which was placed inside a crucible. Ethanol-water mixture $(150 \mu \mathrm{L})$ was added into the vessel and parafilm was used to cover the crucible. After 5-minutes exposure to the ethanol vapors, photoluminescent emission spectral changes of the sensor were measured under an irradiation on $278 \mathrm{~nm}$ light source. Four ethanol containing commercial products were employed to evaluate the sensor capability. As much as $150 \mu \mathrm{L}$ of the sample was fumed to the sensor material at the optimum exposure time and then the emission spectral changes of the sensor material were recorded with the same procedure. The LoD was calculated according to the following equation:

$$
L o D=\frac{3 \times \text { standard error of intercept }}{\text { slope }}
$$

\section{Result and Discussion}

Material [1] gave emission intensity with a peak centered at $609 \mathrm{~nm}$ under $278 \mathrm{~nm}$ light irradiation for excitation wavelength, as shown in Figure 2. Photoluminescent emission of [1] has been previously studied and was classified as phosphorescent compound 23). Excitation at $278 \mathrm{~nm}$ could be considered as a transition from ${ }^{1} \mathrm{LMMCT}$ (ligand to metal-metal charge transfer) ground state to its excited state $\left({ }^{1} \mathrm{LMMCT}^{*}\right)$. The sensor molecule underwent a non-radiative transition from ${ }^{1} \mathrm{LMMCT}^{*}$ to a spin-forbidden ${ }^{3} \mathrm{MM}$ state. Phosphorescent of this material was resulted from the electronic transition of its triplet state of the metallophilic bonding $\left({ }^{3} \mathrm{MM}\right)$ between $\mathrm{Au}(\mathrm{I})-\mathrm{Au}(\mathrm{I})$ to the singlet ground state of the charge transfer from ligand to metal-metal bonding ( $\left.{ }^{1} \mathrm{LMMCT}\right){ }^{16,18-20,24-27)}$. Therefore, the emission of the used material was found at $609 \mathrm{~nm}$ that is similar to previously reported for the complex with phosphorescent property.

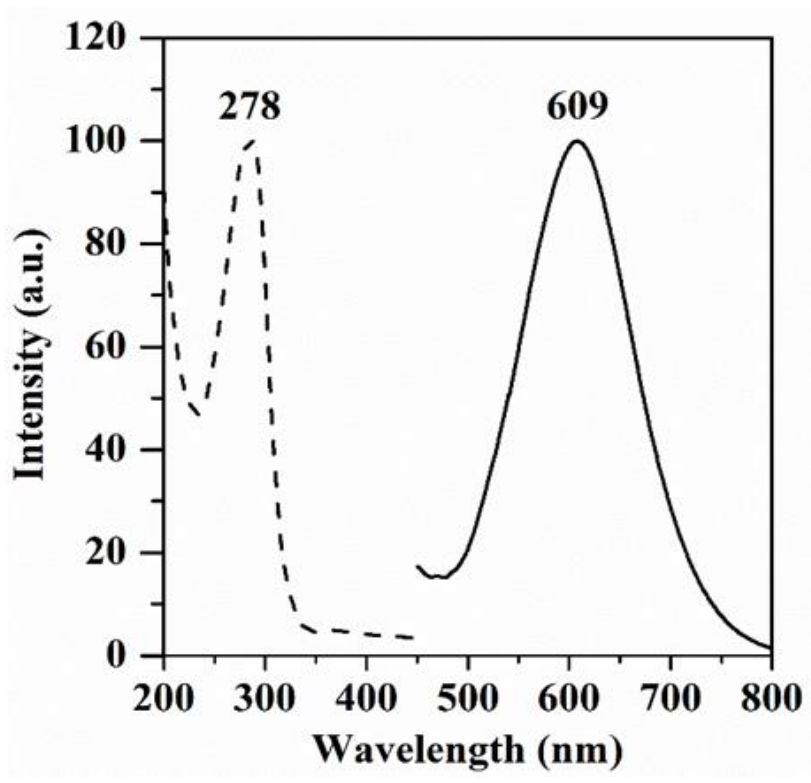

Fig. 2: Excitation (dashed line) and emission (solid line) spectra of material [1]

The correlation graph between the volume fraction of ethanol concentration and the relative changes in its 
emission intensity (Io/I) at various exposure times (up to 5 minutes) is shown in Figure 3. The higher volume fraction in the mixture solution gave a higher amount of the ethanol vapor exposure to the sensor materials [1]. The quenching of its emission intensity at $609 \mathrm{~nm}$ was significantly reduced when the concentration of ethanol was increased up to $50 \%$. It was then constantly reduced with increment of ethanol vapors with concentration of $75 \%$ and $100 \%$. The final quenching of its emission intensity with $100 \%$ ethanol was achieved up to around $60 \%$.

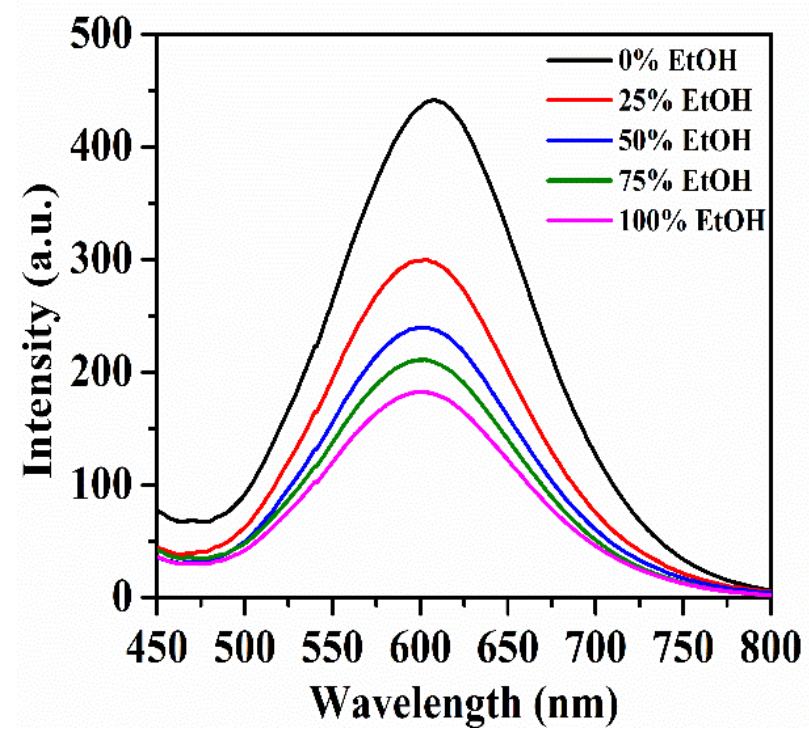

Fig. 3: Emission spectral changes of material [1] with variation of ethanol concentration

By using the emission spectral changes as shown in Figure 3, it is possible to evaluate the relationship between emission changes and the increment of ethanol concentration. This quenching phenomenon was figured from the undistinguishable plot between various concentrations in 5 minutes of the exposure. Figure 4 shows the relationship that is proportional to the volume fraction of ethanol on the sample.

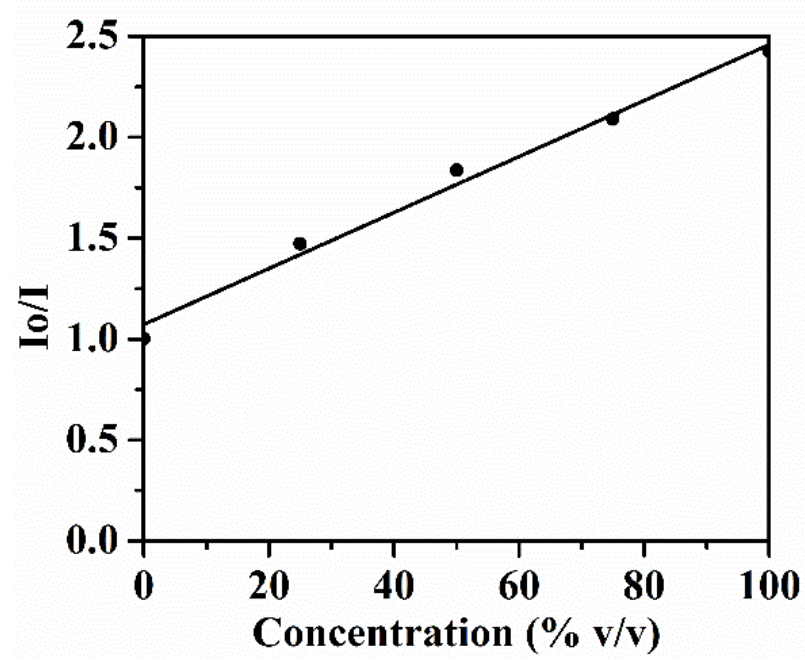

Fig. 4: Relative intensity Io/I of material [1]
Furthermore, the sensor material [1] was tested to real disinfectant and beverage products for evaluating the validity of ethanol quantification as proposed in this work. Two representatives of each disinfectant and beverage samples were Onemed Alkohol 95\%, Onemed Alkohol $70 \%$, Johny Walker ${ }^{\circledR}$ Black Label ${ }^{\circledR}$, and Beefeater Gin, respectively. By the label, the ethanol contents of those products shall be found with concentration of $95 \%, 70 \%$, $40 \%$, dan $47 \%$. Using this vapochromic sensor, it was found that the detected ethanol contents for Onemed Alkohol 95\%, Onemed Alkohol 70\%, Johny Walker ${ }^{\circledR}$ Black Label ${ }^{\circledR}$, and Beefeater Gin were 93\%, 69\%, 44\%, and $47 \%$, respectively. From these results, the accuracy was achieved up to $96 \%$. Such sensing performance of material [1] is remarkable as shown in Table 1.

Table 1. Ethanol content of four tested products

\begin{tabular}{|c|c|c|}
\hline \multirow{2}{*}{ Tested Product } & \multicolumn{2}{|c|}{ Ethanol Content } \\
\cline { 2 - 3 } & (\% measured) & (\% by label) \\
\hline $\begin{array}{c}\text { Onemed Alkohol } \\
95 \%\end{array}$ & 93 & 95 \\
\hline $\begin{array}{c}\text { Onemed Alkohol } \\
70 \%\end{array}$ & 69 & 70 \\
\hline Johny Walker & & \\
Black Label ${ }^{\circledR}$ & 44 & 40 \\
\hline Beefeater Gin & 47 & 47 \\
\hline
\end{tabular}

Linear fitting of the plotted graphic in Figure 4 shows that the R-squared value is 0.988 . The intercept and slope values of the plot are $1.07 \pm 0.05$ and $(1.39 \pm 0.09) \times 10^{-2}$, respectively. Moreover, by using equation (1), the sensing capability of [1] was found to have sensitivity with LoD as lows as $11.7 \%$. These findings are useful for the chemosensor field as well as the analytical field due to a simple and valid process which rarely reported before. Furthermore, a prototype for a handheld device could be built to perform portable ethanol quantification so that it can be used in the field.

In this work, the prepared material [1] has been used as a vapochromic chemosensor for the ethanol quantification. Because of that, the sensor material [1] was placed on the crucible while the ethanol-water mixture was added near the sensor materials without any direct physical contact. As it is known that the vapor pressure of ethanol is higher than that of water, hence ethanol is easier to evaporate and reach the surface of the sensor material. In this case, ethanol vapor will interact with the methoxy moieties of 4-(3,5-dimethoxybenzyl)-3,5-dimethyl pyrazolate ligand through a weak interaction using hydrogen bonding ${ }^{23)}$. On that hydrogen bonding, the hydroxyl group of ethanol acts as a proton donor while the methoxy substituent becomes 
the proton acceptor. This interaction caused interruption of a weak $\mathrm{Au}(\mathrm{I})-\mathrm{Au}(\mathrm{I})$ metallophilic bonding. As the $\mathrm{Au}(\mathrm{I})-\mathrm{Au}(\mathrm{I})$ bonds became less frequent, the material lost its light-emitting capability, indicating from the quenching of its photoluminescent spectrum ${ }^{28)}$. The schematic image for the representation of the plausible interaction between ethanol vapors and sensor materials [1] was displayed in Figure 5.

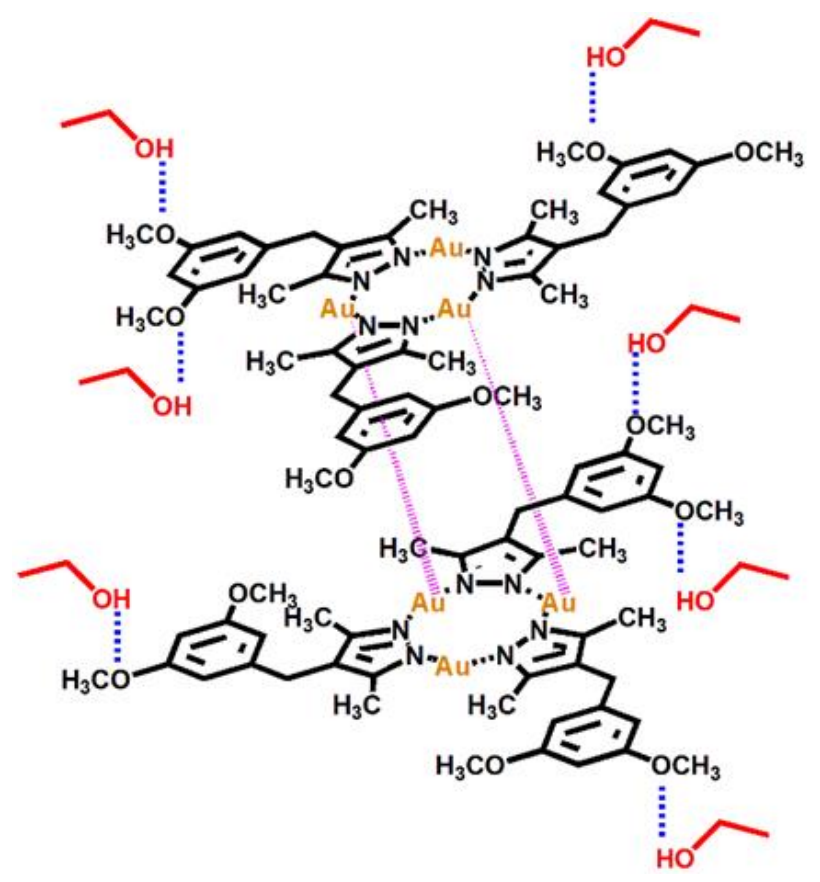

Fig. 5: Dimer of trimer of gold(I) 4-(3,5-dimethoxybenzyl)3,5-dimethyl pyrazolate complex with purple and blue dash line indicating metallophilic and hydrogen bonding, respectively.

\section{Conclusion}

Analytical importance of material [1] complex for the quantifying ethanol has been studied by using vapochromic detection. Based on the photoluminescent properties of this sensor material at $609 \mathrm{~nm}$ with an excitation at $278 \mathrm{~nm}$, a novel method has been achieved for the ethanol quantification. In this case, exposure of ethanol vapors to the sensor material [1] was observed to cause quenching in its photoluminescent spectrum. The optimum exposure time was 5 minutes to give the highest emission changes up to $60 \%$. Furthermore, the volume fraction of ethanol in aqueous solution was linearly quenched by the emission of the sensor material with LoD of $11.7 \%$. Indeed, this phenomenon is promising to be used analytically for the quantification of ethanol content in the real sample with accuracy of $96 \%$. The reliability of this method was satisfied enough through a test on four ethanol containing disinfectant and beverage products with high accuracy.

\section{Acknowledgements}

This work was financially supported by Higher Education Excellent Applied Research (PTUPT) Grant 2019 with a contract number 006/MACHUNG/LPPM/SP2H-LIT/III/2019

(041/SP2H/LT/MULTI/L7/2019) through Directorate General of Strengthening Research and Development, The Ministry of Research, Technology and Higher Education, The Republic of Indonesia. The authors thank Ma Chung Research Center for Photosynthetic Pigments, Universitas Ma Chung, Malang for the facilities.

\section{References}

1) T. Arndt, S. Schröfel, B. Güssregen, and K. Stemmerich, "Inhalation but not transdermal resorption of hand sanitizer ethanol causes positive ethyl glucuronide findings in urine," Forensic Sci. Int., 237, 126 (2014).

2) K.A. Reynolds, J.D. Sexton, T. Pivo, K. Humphrey, R.A. Leslie, and C.P. Gerba, "Microbial transmition in an outpatient clinic and impact of an intervention with an ethanol-based disinfectant" Am. J. Infect. Control., 47, 128 (2019).

3) S.S. Bozkurt, E. Merdivan, and Y. Benibol, "A fluorescent chemical sensor for ethanol determination in alcoholic beverages", Microchim. Acta., 141 (2010).

4) K. Uddin, I.I, El-Sharkawy, T. Miyazaki, and B.B, Saha, "Thermodynamic analysis of adsorption cooling cycle using ethanol-surface treated maxsorb III pairs", Evergreen, 01, 01 (2014).

5) M. Zachut, F. Shapiro, and N. Silanikove, "Detecting ethanol and acetaldehyde by simple and ultrasensitive fluorimetric methods in compound foods"., Food. Chem. 201, 270 (2016).

6) A. Debebe, A. Anberbir, M. Redi-Abshiro, B.S. Chandravanshi, A. Asfaw, N. Asfaw, and N. Retta, "Alchol determination in distilled alcohol beverages by liquid phase fourier transform mid-infrared and near-infrared spectrophotometries", Food. Anal. Methods., 10, 172 (2017).

7) M. Stupak, V. Kocourek, I. Kolouchova, and J. Hajslova, "Rapid approach for the determination of alcoholic strength and overall quality check of various sprint drinks and wines using GC-MS", Food. Control., 80, 307 (2017).

8) O.R. Marinho, M.J.A. Lima, F.R.P. Rocha, B.F. Reis, and M.Y. Kamogawa, "A greener, fast, and costeffective smartphone-based digital image procedure for quantification of ethanol in distilled beverages", Microchim. J., 147, 437 (2019).

9) S. Soylemez, S. Goker, and L. Toppare, "A promising enzyme anchoring probe for selective ethanol sensing in beverages", Int. J. Biol. Macromol., 133, 1228 (2019).

10) E.M. Silva, T.B. Tarantino, J.S. Almeida, J.S.R. 
Teixeira, R.M.M. Santana, M.G.A. Korn, and L.S.G. Teixeira, "Determination of ethanol in biodiesel samples using mercaptopropionic acid-capped cadmium telluride quantum dots as photoluminescence probes", Fuel, 238, 425 (2019).

11) P. Imam, Prakoso. T, H.S. Bambang, and M. Gozan, "The effect of outdoor temperature conditions and monoglyceride content on the precipitate formation of biodiesel-petrodiesel blendel fuel (BXX)", Evergreen, 06, 01 (2019).

12) D.A. Wulandari, Nasruddin, and E. Djubaedah, "Thermal behavior and characteristic of Pangandaran natural zeolite", Evergreen, 06, 03 (2019).

13) Z.F. Zahara, "Economic assessment of the sugarcanebased bio-refinery in Indonesia", Evergreen, 05, 02 (2018).

14) J.M. Lorenzo, P.E. Munekata, V. Muchenje, J.A. Saraiva, C.A. Pinto, F.J. Barba, and E.M. Santos, "Bionsensors applied to quantification of ethanol in beverages", Engineering Tools in the Beverage Industry, 447 (2019).

15) M. Enomoto, A. Kishimura, and T. Aida, "Coordination metallacycles of an achiral dendron self-assemble via metal-metal interaction to form luminescent superhelical fibers", J. Am. Chem. Soc., 23, 5608 (2001).

16) A. Kishimura, T. Yamashita, and T. Aida, " Phosphorescent organogels via "metallophilic" interactions for reversible RGB-color switching", $J$. Am. Chem. Soc., 127, 179 (2005).

17) A. Kishimura, T. Yamashita, K. Yamaguchi, and T. Aida, "Rewritable phosphorescent paper by the control of competing kinetic and thermodynamic selfassembling events", Nat. Mater., 4, 546 (2005).

18) H.O. Lintang, K. Kinbara, K. Tanaka, T. Yamashita, and T. Aida, "Self-repair of a one-dimensional molecular assembly in mesoporous silica by a nanoscopic template effect", Angew. Chem. Int. Ed., 49, 4241 (2010).

19) H.O. Lintang, K. Kinbara, T. Yamashita, and T. Aida, "Metal-ion permeation in congested nanochannels: the exposure effect of $\mathrm{Ag}^{+}$ions on the phosphorescent properties of a gold(I)-pyrazolate complex that is confined in the nanoscopic channels of mesoporous silica", Chem. Asian J., 7, 2068 (2012).

20) H.O. Lintang, L. Yuliati, S. Endud, " Phosphorescent sensing and imaging of temperature using mesoporous silica/gold nanocomposites", Mater. Res. Innov., 18, S6-444 (2014).

21) H.O. Lintang, N.F. Ghazalli, and L. Yuliati, "Supramolecular phosphorescent trinuclear copper(I) pyrazolate complexes for vapochromic chemosensors of ethanol, Indones. J. Chem., 17(2), 191 (2017).

22) N.F. Ghazalli, L. Yuliati, and H.O. Lintang, "Molecular self-assembly of group 11 pyrazolate complexes as phosphorescent chemosensors for detection of benzene", IOP Conf. Ser. Mater. Sci. Eng.,
299, 012029 (2018).

23) H.O. Lintang, N.F. Ghazalli, and L. Yuliati, "Supramolecular assembly of group 11 phosphorescent metal complexes for chemosensors of alcohol derivatives", IOP Conf. Ser. Mater. Sci. Eng., 349, 012023 (2018).

24) M.A. Omary, M.A. Rawashdeh-Omary, M.W.A. Gonser, O. Elbjeirami, T. Grimes, T.R. Cundari, H.V.K. Diyabalanage, C.S. Palehepitiya Gamage, and H.V.R. Dias, "Metal effect on the supramolecular stucture, photophysics, and acid-base character if trinuclear pyrazolato coinage metal complexes", Inorg. Chem., 44, 8200 (2005).

25) P.K. Upadhyay, S.B. Marpu, E.N. Benton, C.L. Williams, A. Telang, and M.A. Omary, "A phosphorescent trinuclear gold(I) pyrazolate chemosensor for silver ion detection and remediation in aqueous media", Anal. Chem., 90, 4999 (2018).

26) M.A, Omary, A.A. Mohamed, M.A. RawashdehOmary, and J. P, Fackler Jr, "Photophysics of supramolecular binary stacks consisting of electronrich trinuclear $\mathrm{Au}(\mathrm{I})$ complexes and organic electrophiles", Coord. Chem. Rev., 249, 1372 (2005).

27) M.A. Rawashdeh-Omary, "Remarkable alteration of photophysical properties of cyclic trinuclear complexes of monovalent coinage metals upon interactions with small organic molecules", Comment. Inorg. Chem., 33, 88 (2012).

28) K. Naka, T. Kato, S. Watase, and K. Matsukawa, "Organic vapor triggered repeatable on-off crystalline-state luminescence switching”, Inorg. Chem., 51, 4420 (2012). 